\title{
The epidemiology of Plasmodium
} falciparum and Plasmodium vivax in East Sepik Province, Papua New Guinea, preand post-implementation of national malaria
control efforts

Johanna H. Kattenberg 1,2,3, Dulcie L. Gumal1,9, Maria Ome-Kaius '1,2, Benson Kiniboro', Matthew Philip', Shadrach Jally ${ }^{1}$, Bernadine Kasian ${ }^{1}$, Naomi Sambale ${ }^{1}$, Peter M. Siba', Stephan Karl1,2, Alyssa E. Barry 2,6,7, Ingrid Felger ${ }^{4}$, James W. Kazura ${ }^{5}$, Ivo Mueller ${ }^{2,6,8}$ and Leanne J. Robinson ${ }^{1,2,6,9^{*}}$ (e)

\begin{abstract}
Background: In the past decade, national malaria control efforts in Papua New Guinea (PNG) have received renewed support, facilitating nationwide distribution of free long-lasting insecticidal nets (LLINs), as well as improvements in access to parasite-confirmed diagnosis and effective artemisinin-combination therapy in 2011-2012.

Methods: To study the effects of these intensified control efforts on the epidemiology and transmission of Plasmodium falciparum and Plasmodium vivax infections and investigate risk factors at the individual and household level, two cross-sectional surveys were conducted in the East Sepik Province of PNG; one in 2005, before the scale-up of national campaigns and one in late 2012-early 2013, after 2 rounds of LLIN distribution (2008 and 2011-2012). Differences between studies were investigated using Chi square $\left(x^{2}\right)$, Fischer's exact tests and Student's t-test. Multivariable logistic regression models were built to investigate factors associated with infection at the individual and household level.
\end{abstract}

Results: The prevalence of P. falciparum and P. vivax in surveyed communities decreased from $55 \%$ (2005) to 9\% (2013) and $36 \%$ to $6 \%$, respectively. The mean multiplicity of infection (MOI) decreased from 1.8 to 1.6 for $P$. falciparum $(p=0.08)$ and from 2.2 to 1.4 for $P$. vivax $(p<0.001)$. Alongside these reductions, a shift towards a more uniform distribution of infections and illness across age groups was observed but there was greater heterogeneity across the study area and within the study villages. Microscopy positive infections and clinical cases in the household were associated with high rate infection households ( $>50 \%$ of household members with Plasmodium infection).

Conclusion: After the scale-up of malaria control interventions in PNG between 2008 and 2012, there was a substantial reduction in P. falciparum and P. vivax infection rates in the studies villages in East Sepik Province. Understanding the extent of local heterogeneity in malaria transmission and the driving factors is critical to identify and implement

\footnotetext{
*Correspondence: leanne.robinson@burnet.edu.au

${ }^{9}$ Disease Elimination Program, Vector-borne Diseases and Tropical Public

Health Group, Burnet Institute, 85 Commercial Rd, Melbourne, VIC 3004,

Australia

Full list of author information is available at the end of the article
}

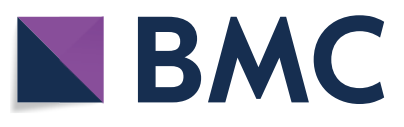

(c) The Author(s) 2020. This article is licensed under a Creative Commons Attribution 4.0 International License, which permits use, sharing, adaptation, distribution and reproduction in any medium or format, as long as you give appropriate credit to the original author(s) and the source, provide a link to the Creative Commons licence, and indicate if changes were made. The images or other third party material in this article are included in the article's Creative Commons licence, unless indicated otherwise in a credit line to the material. If material is not included in the article's Creative Commons licence and your intended use is not permitted by statutory regulation or exceeds the permitted use, you will need to obtain permission directly from the copyright holder. To view a copy of this licence, visit http://creativeco mmons.org/licenses/by/4.0/. The Creative Commons Public Domain Dedication waiver (http://creativecommons.org/publicdomain/ zero/1.0/) applies to the data made available in this article, unless otherwise stated in a credit line to the data. 
targeted control strategies to ensure the ongoing success of malaria control in PNG and inform the development of tools required to achieve elimination. In household-based interventions, diagnostics with a sensitivity similar to (expert) microscopy could be used to identify and target high rate households.

Keywords: Malaria, Plasmodium falciparum, Plasmodium vivax, Epidemiology, Malaria control, Spatial heterogeneity, LLINS

\section{Background}

Papua New Guinea (PNG) has the highest transmission of malaria in the Western Pacific Region, where it accounted for $80 \%$ of the reported confirmed cases in 2018 [1]. The majority of the population in malariaendemic areas have some degree of natural immunity and, therefore, the prevalence of malaria infection and incidence of morbidity are highest in young children and pregnant women. In the coastal and lowland inland areas along the north coast perennial high intensity malaria transmission is present [2-8].

East Sepik Province (ESP) has historically been an area of PNG with a high malaria burden, with a peak prevalence of $70 \%$ (by light microscopy (LM)) in children 5-9 years of age in the early 1990 's [3], whilst more recent studies indicate a lower prevalence $[5,9]$. The Anopheline spp. fauna in PNG is diverse and includes 16 species [10]. The principal malaria vectors in PNG are members of the Anopheles punctulatus group of mosquitoes, of which An. punctulatus, Anopheles koliensis, Anopheles farauti, and Anopheles farauti 4 have been incriminated as major vectors [10-14]. The different species have different biting cycles: An. farauti tend to bite mostly during the early hours of the evening, and in the case of $A n$. punctulatus and An. koliensis, peak activity takes place in the early hours of the morning [2].

Plasmodium falciparum and Plasmodium vivax are the most abundant species in PNG, though Plasmodium malariae and Plasmodium ovale are also present, usually in combination with the former two species [15]. Plasmodium vivax was the predominant species prior to the introduction of mass spraying and drug administration programmes in the 1950's, which were intended to eliminate malaria $[2,16,17]$, These efforts were subsequently abandoned in the 1970's and a resurgence of $P$. falciparum followed, which remains the dominant species today [2, 17]. However, in the past decade, renewed malaria control efforts initiated by the PNG National Department of Health with support from The Global Fund to fight AIDs, $\mathrm{TB}$ and malaria have once again significantly reduced the burden of malaria in PNG [18-22]. This National Malaria Control Programme (NMCP) has focused on the nationwide distribution of free LLINs on a 3-yearly cycle since 2008 , greater availability of prompt diagnosis and effective treatment through the introduction of rapid diagnostic tests (RDTs) and artemisinin-based combination therapy (ACT) in 2011-2012 and a behaviour change campaign, "Yumi rausim malaria", focused on improving understanding of the best options for prevention and treatment of malaria [18, 21, 23]. ESP was among the first Provinces in PNG where the LLIN distribution campaign was implemented, which together with the availability of historical data makes it an ideal location to investigate the changing epidemiology of malaria in PNG.

While the previously reported reduction in nationwide prevalence and incidence of malaria and all-cause mortality rates in young children are significant achievements $[18,21-24]$, important questions related to the nature of the epidemiological transition and long-term impact of intensified control on parasite-host-vector interactions remain unresolved. Sustained reduction in malaria transmission can lead to a decrease in naturally acquired immunity and consequently, a shift in the peak burden of malaria infection and illness to older age groups and change other risk factors. A declining burden of malaria illness and high-density parasite infections can also mask a substantial community burden of low-density but gametocytaemia infections that sustain transmission [25-27]. In addition, the possible differential effects of these interventions on the various Plasmodium species is important to consider in co-endemic regions such as PNG, given the distinct biological differences of the two main Plasmodium species. While declining prevalence and morbidity have been documented on a regional level, the effects of decreasing malaria transmission on a smaller geographical scale remain to be investigated. Heterogeneities in transmission and disease burden have been described at various scales in PNG [4, 21, 25] and can be a major challenge to further reducing the burden of malaria, as hotspots can act as the source of infection for other neighbouring areas [28], and especially $P$. vivax can be resilient [25].

To investigate the impact of the renewed malaria control efforts on the epidemiology of malaria within communities, data from two cross-sectional community surveys conducted in the Maprik and Wosera-Gawi districts of East Sepik Province, PNG; one in April-May 2005, before the implementation of national LLIN distribution campaign and one in October 2012-February 2013, were directly compared. Risk factors for parasite 
prevalence, and spatial heterogeneity were investigated in addition to gametocytaemia and complexity/multiplicity of infection. Understanding the key factors related to heterogeneity and residual malaria transmission in PNG is critical to support the desired transition from nation-wide malaria control to sub-national elimination strategies.

\section{Methods}

\section{Study design}

Two cross-sectional community surveys were conducted in the Maprik and Wosera-Gawi districts in the East Sepik Province of PNG; one in April-May 2005 [9], before the implementation of national LLIN distribution campaign and one in October 2012-February 2013. The 1st round of LLIN distribution in ESP took place in 2008, followed by a second round in 2011-2012. LLINs in the study area in ESP were distributed at most 12 months prior to the 2012/13 survey: September 2011 (Brukham, Ulupu and Ilahita catchement areas) and October 2012 (Wombisa and Burui catchement areas). Introduction of a test-and-treat approach and a switch to artemether-lumefantrine ( $\mathrm{AL}$ ) as first-line treatment and formal adoption of 14 days $0.25 \mathrm{mg} / \mathrm{kg}$ primaquine for vivax-confirmed malaria occurred at the end of 2011/ beginning of 2012. The Maprik and Wosera-Gawi districts, consist of an area of over $160 \mathrm{~km}^{2}$ with low hills, plains and riverine plains with a wet tropical climate [3, 9]. The natural vegetation is lowland hill forest that has mostly been replaced by re-growth following cultivation and wide grasslands on the plains near the Sepik River. The people in this area live in villages of hundred to several hundred individuals and the villages are sometimes divided in geographically distinct hamlets. The majority of the people live from subsistence farming. There are several government health centres, church health centres and smaller aid posts in the area and the referral hospital is in Maprik.

All eligible and willing residents of households in the local communities in the study area were invited to participate and following written informed consent, demographic information (age, gender, familial relationship, bed net use), history of febrile illness, household or village location by GPS receiver and blood samples were collected. The design of both studies was similar, and details of the 2005 study have been previously described [9]. All details of the recent cross-sectional are described below. In the 2005 study questions related to bed nets were not directed to insecticide treated nets (ITNs) or LLINs in particular, and are likely to be untreated nets. In 2012-2013, after the start of the large-scale LLIN campaigns, questions were asked specifically about LLINs and not ITNs or untreated nets. Therefore, when variables are reported where the 2005 study is included, the term bed nets will be used, while in the 2012-2013 study the term LLINs can be applied.

Capillary blood $(250-300 \mu \mathrm{L})$ was collected into $\mathrm{K}+$ EDTA microtainers, thick/thin films were prepared and haemoglobin levels were measured (Hemocue). The collected blood was centrifuged, the plasma removed and stored at $-80{ }^{\circ} \mathrm{C}$, and the red cell pellet stored at $-20^{\circ} \mathrm{C}$ until DNA extraction. If febrile illness was reported, a rapid malaria diagnostic test (Carestart $\mathrm{Pf} / \mathrm{Pan}$ ) was performed and those positive by RDT treated with artemether-lumefantrine (Coartem). For RNA preservation, $50 \mu \mathrm{L}$ of whole blood was immediately transferred to a tube containing $250 \mu \mathrm{L}$ of RNAProtect (Qiagen) and stored at $-80{ }^{\circ} \mathrm{C}$ within $8 \mathrm{~h}$ of collection until RNA extraction.

\section{Plasmodium spp. detection}

Giemsa-stained thick and thin films from the 2005 survey were examined by LM (minimum of 200-high powered fields) by two independent experienced microscopists, with discrepancies adjudicated by a third independent microscopist, as previously described [9]. All slides collected during the 2012/13 study, were similarly examined once by experienced microscopists. Slides from LM and/or PCR positive individuals and a random selection of negative slides were re-examined by an independent microscopist with discrepancies adjudicated by a third WHO-certified Level 1 or 2 microscopist. Parasite densities were calculated from the number of parasites per 200 or 500 white blood cells (WBCs) (depending on parasitaemia) and an assumed total peripheral WBC count of $8000 / \mu \mathrm{L}$ [29], with the final density taken as the geometric mean of the two values.

The presence of parasite DNA in all blood samples was investigated by molecular methods (MM, i.e. qPCR or LDR-FMA). In 2005 DNA was extracted from red blood cell pellets using QIAmp 96 DNA Blood kits (Qiagen) and a post-PCR, ligase detection reaction/microsphere assay (LDR-FMA) was used to determine the presence of $P$. falciparum, $P$. vivax, $P$. malariae and $P$. ovale $[9,30]$. In the 2012/13 survey, DNA was extracted from the equivalent of $200 \mu \mathrm{L}$ whole blood using the Favorgen 96-well Genomic DNA Extraction Kit (Favorgen) following the manufacturer's instructions and eluted in $200 \mu \mathrm{L}$. Initially a generic quantitative PCR (QMAL) that amplifies a conserved region of the $18 \mathrm{~S}$ rRNA gene was run on all samples [31]. Species-specific quantitative PCRs (qPCR) were then performed on all positive samples as described [32]. The qPCR was previously directly compared to the LDR-FMA and assays are approximately equivalent in sensitivity and specificity [32]. Copy numbers were 
quantified based on serial dilutions of plasmid controls run in parallel.

\section{Gametocyte detection}

The number of observed $P$. falciparum (2005 and 2012/13) and/or P. vivax (2012/13 only) gametocytes were recorded separately from asexual stages during microscopic examination of all blood slides. Gametocyte detection by qRT-PCR was performed on samples from 2012/13: RNA was extracted from all $P$. falciparum and/or P. vivax qPCR-positive samples using the Qiagen RNeasy plus 96 kit, according to the manufacturer's procedures. A genomic DNA removal by gDNA eliminator columns and DNase (Qiagen) step was included in the procedure. Absence of gDNA was confirmed by qPCR and presence of parasite RNA after extraction was verified by qRT-PCR with the same primers and probe as the QMAL qPCR described above. P. falciparum and $P$. vivax gametocytes were detected by qRT-PCR of the highly expressed gametocyte markers $p f s 25$ and $p v s 25$ as previously described [31]. The limit of detection of the $p f s 25$ and pvs 25 qRT-PCRs in the laboratory set up in PNG, were 6 copies/transcript per reaction for both assays.

\section{Genotyping}

To genotype $P$. falciparum and $P$. vivax LDR-FMA/qPCR positive samples, high-resolution Pfmsp2, Pvmsp1f3 and PvMS2 genotyping was performed as previously described [33, 34]. Briefly, for P. falciparum a nested multiplex PCR approach was used to amplify 3D7 and/ or FC27 family alleles of Pfmsp 2 using family-specific primers labelled with a fluorescent dye, or a multiplex primary PCR was used to amplify the markers Pvmsp1F3 and PvMS2 with fluorescently labelled primers. The PCR products were analysed by $1.5 \%$ agarose gel electrophoresis and the number and size of alleles were then determined by capillary electrophoresis using a 23 ABI 3730XLs platform (Macrogen, Korea) with the internal size standard GSLIZ500 and data were subsequently analysed using GeneMarker 2.4.0 demo version (SoftGenetics). The multiplicity of infection (MOI) for $P$. falciparum was defined as the number of $P$ fmsp 2 alleles counted within a sample, and $P$. vivax MOI was defined by the number of Pvmsp1f3 or PvMS2 alleles, whichever was higher.

\section{Data analysis}

Raw data from the 2005 survey [9] was reanalysed to compare prevalence and predictors with data from the 2012/13 survey. Clinical malaria cases were defined as febrile illness (current or previous $48 \mathrm{~h}$ ) in the presence of $P$. vivax or $P$. falciparum asexual parasites by LM (any density). Symptomatic infections were defined as febrile illness (current or previous $48 \mathrm{~h}$ ) in the presence of parasites as detected by LM and/or MM. Parasite densities were $\log$ transformed and the geometric mean per $\mu \mathrm{L}$ whole blood are reported. Four categories were used to describe anaemia: non-anaemia, mild, moderate or severe, which were defined based on haemoglobin concentrations (measured by Hemocue) and stratified by age and gender as per the WHO recommendations (Additional file 1) [35]. On average, there were 3.7 people in a household (3.8 in 2005; 3.5 in 2012-2013). A high-infection rate household was defined on the basis of having more than $50 \%$ of household members with a Plasmodium infection (determined by molecular method).

Differences between the two studies were investigated using Chi square $\left(x^{2}\right)$ and Fischer's exact tests for categorical characteristics and Student's t-test for normallydistributed continuous variables. Tests were two-tailed and the confidence level was set at 95\%. Univariable analysis of factors associated with $P$. falciparum or $P$. vivax infection (determined by MM and/or LM) and high rate household were conducted using logistic regression. Multivariable logistic regression models were built with variables with $\mathrm{p}<0.15$ in univariate analysis and variables were selected using likelihood methods for models with minimal Akaike information criterion (AIC). Analyses were performed using Stata 12. Genetic diversity analyses were done using FSTAT software version 2.9.3.2 to define allele frequencies, and the expected heterozygosity $(\mathrm{He})$. Household, village and health facility location data were collected using a handheld GPS receiver (Garmin GPSmap62sc). Maps were constructed with collected GPS coordinates using ARC GIS Pro 10.4

\section{Results \\ Study characteristics}

A total of 2744 participants from 15 villages in five distinct geographical areas of East Sepik Province participated in the 2005 cross-sectional survey. Of these 121 (4.4\%) were excluded because of missing demographic or LM data, while insufficient finger-prick blood sample for LDR-FMA analysis led to exclusion of an additional 96 (3.5\%) individuals. Overall 2527 participants from 659 households with complete demographic and infection status data were available for comparison with 2012/13 data. A total of 2500 participants in 14 villages from the same areas participated in the 2012/13 cross-sectional survey. Of these, $14(0.6 \%)$ were excluded from the analysis because of missing LM results. Overall, 2486 participants from 704 households with complete demographic and infection status data were available.

The two studies were very comparable in their design, however, they differed in the demographic and clinical characteristics of the participants (Table 1 and Additional 
Table 1 Summary of demographic and clinical characteristics of study participants

\begin{tabular}{|c|c|c|c|c|c|}
\hline & \multicolumn{2}{|l|}{2005} & \multicolumn{2}{|l|}{2013} & \multirow[t]{2}{*}{$p$-value } \\
\hline & $\mathbf{n}$ & $\%$ & $\mathbf{n}$ & $\%$ & \\
\hline Number of participants & 2527 & & 2486 & & \\
\hline Gender (female) & 1331 & 52.7 & 1438 & 57.8 & $<0.001$ \\
\hline Age in years (median [range]) & $17[0-80]$ & & $22[0-68]$ & & $<0.0001$ \\
\hline Reported use of bed nets/LLINs & 2231 & 88.3 & 2348 & 94.9 & $<0.001$ \\
\hline History of recent malaria infection & 409 & 16.3 & 137 & 5.5 & $<0.001$ \\
\hline History of recent malaria treatment & 195 & 8.0 & 145 & 5.87 & 0.003 \\
\hline Anaemia & $2131 / 2486$ & 85.7 & $1719 / 2382$ & 72.2 & $<0.001$ \\
\hline Current or recent reported febrile illness & 186 & 7.4 & 356 & 14.4 & $<0.001$ \\
\hline Clinical malaria (due to P. falciparum and/or P. vivax) & 92 & 3.6 & 58 & 2.3 & 0.007 \\
\hline
\end{tabular}

A more detailed comparison can be found in Additional file 2. Italics $p$-values are considered statistically significant $(p<0.05)$

file 2). Median age in 2005 was 17 years (range 2.5 weeks80 years) and 22 in 2012/13 (range 6 months - 68 years). There were three villages from the 2005 study that weren't surveyed in $2012 / 2013$, instead two other villages from the same areas were included. As expected after two rounds of LLIN distribution (2008 and 2011/12), significantly more participants reported using LLINs in 2012/2013 (94.9\%) compared to bed nets in 2005 (88.3\%) (Table 1). The prevalence of clinical episodes of malaria (P. falciparum and/or P. vivax) had dropped from $3.6 \%$ to $2.3 \%(\mathrm{p}=0.007)$. There was a lower prevalence of anaemia in 2012/13, and accordingly, mean haemoglobin levels were significantly higher in 2012/13 $(11.1 \pm 1.8 \mathrm{~g} / \mathrm{dL})$ compared to $2005(10.5 \pm 1.7 \mathrm{~g} / \mathrm{dL} ; \mathrm{p}<0.001)$ (Table 1$)$. In addition, a higher proportion of individuals reported a current or recent febrile illness in 2012/13 (14.4\% vs 7.4\% $\mathrm{p}<0.001)$.

\section{Prevalence of Plasmodium spp. infections in 2005 compared to 2012/13}

The prevalence of malaria infections decreased from $44.4 \%$ to $8.3 \%$ by LM and $73.0 \%$ to $12.2 \%$ by molecular methods (MM) (Table 2). The species composition remained fairly similar, with $P$. falciparum the predominant species in both years $(75.2 \%$ of all infections in 2005 and $70.0 \%$ in $2012 / 13$ by $M M, p=0.052, \chi^{2}$ ), followed by $P$. vivax (48.9\% of all infections in 2005 , and $45.9 \%$ in $2012 / 13$ by $\left.M M, p=0.335, x^{2}\right)$. The prevalence of both species dropped with similar proportions; in other words, for both species the prevalence in 2012/2013 was roughly $16 \%$ of the prevalence in 2005 (Table 2 ). A lower proportion of infections were $P$. malariae $\left(\mathrm{p}<0.001, \mathrm{X}^{2}\right)$ in 2012/13 compared to 2005 while the proportion of $P$. ovale by MM remained similar. The majority of mixed infections in both years consisted of $P$. falciparum - $P$. vivax co-infections, followed by $P$. falciparum with $P$. malariae and/or P. ovale, as determined with MM. The proportion of $P$. falciparum infections that were submicroscopic decreased significantly from 2005 (47.2\%) to 2012/13 (37.4\%; $\mathrm{p}=0.006)$, but not for $P$. vivax (60.4\% vs $\left.54.0 \% ; \mathrm{p}=0.139, \mathrm{X}^{2}\right)$. The geometric mean density of parasites by microscopy was similar in both years. There was a significant increase in the proportion of malaria infections with any species that were symptomatic, increasing from $7.0 \%$ in 2005 to $25.3 \%$ in $2012 / 13\left(\mathrm{p}<0.001, \chi^{2}\right)$, as there was a higher rate of people reporting febrile illness in 2012-2013 (Table 1).

The proportion of $P$. falciparum infected individuals with gametocytes detected by LM increased from $10.6 \%$ in 2005 to $23.7 \%$ in $2012 / 13$ (Table 2). The presence of $P$. falciparum and $P$. vivax gametocytes in the 2012/13 survey was also investigated with a qRT-PCR detecting gametocyte specific RNA, and the proportion of $P$. falciparum infections with gametocytes $(51.4 \%)$ by that method was significantly higher than with LM $(\mathrm{p}<0.001$, $\mathrm{X}^{2}$ ). Plasmodium vivax gametocytes detected by LM were not recorded in 2005. In 2012/13, the prevalence of P. vivax gametocytes was $0.8 \%$ by LM and $0.9 \%$ by qRTPCR (Table 2).

\section{Comparing risk factors for Plasmodium spp. infections and illness}

Village of residence was a risk factor for parasite infection in both surveys (Table 3 ). In addition, moderate or severe anaemia was a strong predictor for $P$. falciparum infection in both surveys, but not for P. vivax (Table 3). While males were more likely to be $P$. falciparum infected than women in 2005 (aOR 1.2 [1.01-1.4], $\mathrm{p}=0.04$ ), there was no difference in 2012-2013. In 2012-2013, current or recent fever was a predictor of $P$. falciparum infection (aOR 2.0 [1.3-3.1], $\mathrm{p}=0.005$ ). In contrast, participants with recent/current febrile illness were more likely to be 
Table 2 Prevalence of Plasmodium spp. infections of study participants

\begin{tabular}{|c|c|c|c|c|c|}
\hline & $2005(n=2527)$ & & $2013(n=2486)$ & & $p$-value \\
\hline \multicolumn{6}{|l|}{ Parasite detection by light microscopy } \\
\hline All species & $1121 / 2527$ & $44.4 \%$ & $206 / 2486$ & $8.3 \%$ & $<0.001$ \\
\hline P. falciparum & $756 / 2527$ & $29.9 \%$ & $139 / 2486$ & $5.6 \%$ & $<0.001$ \\
\hline Asexual parasites & $730 / 2527$ & $28.9 \%$ & $128 / 2486$ & $5.2 \%$ & $<0.001$ \\
\hline Gametocytes & $80 / 2527$ & $3.2 \%$ & $33 / 2486$ & $1.3 \%$ & $<0.001$ \\
\hline Geometric mean density (SD) & 464.2 & (6.8) & 487.3 & (9.3) & 0.798 \\
\hline P. vivax & $368 / 2527$ & $14.6 \%$ & $69 / 2486$ & $2.8 \%$ & $<0.001$ \\
\hline Asexual parasites & & & $69 / 2486$ & $2.8 \%$ & \\
\hline Gametocytes & & & $19 / 2486$ & $0.8 \%$ & \\
\hline Geometric mean density (SD) & 193.2 & $(4.2)$ & 218.5 & (5.6) & 0.531 \\
\hline P. malariae & $99 / 2527$ & $9.0 \%$ & $6 / 2486$ & $0.2 \%$ & $<0.001$ \\
\hline P. ovale & $0 / 2527$ & $0.0 \%$ & $2 / 2486$ & $0.1 \%$ & 0.246 \\
\hline Mixed any species & $100 / 2527$ & $6.5 \%$ & $9 / 2486$ & $0.4 \%$ & $<0.001$ \\
\hline \multicolumn{6}{|l|}{ Parasite detection by molecular method } \\
\hline All species & $1844 / 2527$ & $73.0 \%$ & $303 / 2486$ & $12.2 \%$ & $<0.001$ \\
\hline P. falciparum & $1387 / 2527$ & $54.9 \%$ & $212 / 2486$ & $8.5 \%$ & $<0.001$ \\
\hline Gametocytes & NA & & $94 / 2486$ & $3.8 \%$ & \\
\hline P. vivax & $901 / 2527$ & $35.7 \%$ & $139 / 2486$ & $5.6 \%$ & $<0.001$ \\
\hline Gametocytes & NA & & $23 / 2486$ & $0.9 \%$ & \\
\hline P. malariae & $338 / 2527$ & $13.4 \%$ & $28 / 2486$ & $1.1 \%$ & $<0.001$ \\
\hline P. ovale & $121 / 2527$ & $4.8 \%$ & $29 / 2486$ & $1.2 \%$ & $<0.001$ \\
\hline Mixed any species & $723 / 2527$ & $28.6 \%$ & $93 / 2486$ & $3.7 \%$ & $<0.001$ \\
\hline Mixed with P. falciparum & $683 / 2527$ & $27.0 \%$ & $86 / 2486$ & $3.5 \%$ & \\
\hline Mixed non-P. falciparum & $40 / 2527$ & $1.6 \%$ & $7 / 2486$ & $0.3 \%$ & \\
\hline Symptomatic infections of any species & $132 / 2527$ & $5.2 \%$ & $80 / 2486$ & $3.2 \%$ & $<0.001$ \\
\hline
\end{tabular}

Italics $p$-values are considered statistically significant $(p<0.05)$

P. vivax infected in 2005, but not in 2012/13 (Table 3), and recent anti-malarial treatment was associated with reduced risk of $P$. vivax in 2005. Infection with the other species was a predictor for both $P$. falciparum and $P$. vivax in 2012-2013 (Table 3).

Although there was a considerable reduction in the overall prevalence of malaria between 2005 and 2012/13, there was no obvious shift in the age of peak prevalence of $P$. falciparum and P. vivax infections (Fig. 1, Table 3). However, a more uniform distribution of infections across all age groups was observed in 2012/13 compared to 2005 , with age no longer a significant predictor of $P$. falciparum infection in 2012/13 (Table 3). Plasmodium falciparum infections were most frequent in older children, especially in 2005 (12-20 years by MM in 2005 and 6-20 years by MM in 2012-2013) (Fig. 1). Plasmodium vivax prevalence was highest in younger children (3-12 years by MM) compared to P. falciparum (Fig. 1 and Table 3). Compared to 2005, an increase in the proportion of symptomatic infections was seen in most age groups in 2012-2013 (Fig. 1), and age was not a significant predictor of symptomatic infections in 2012-2013 (logistic regression, $\mathrm{p}>0.05$ ). The increase in proportion of symptomatic infections in $2012 / 13$ is especially large in children and adults above 12 years; fivefold in the case of $P$. falciparum and 9 to 18 -fold in the case of $P$. vivax infections. None of the $P$. falciparum infections observed in 2012/13 between the ages of $0-3$ years were accompanied with fever (Fig. 1).

The decrease in the prevalence of $P$. falciparum and $P$. vivax was much greater in some villages than in others, indicative of heterogeneous transmission (Fig. 2). Of the 12 villages sampled in both years, there were 6 villages where the malaria prevalence by MM in $2012 / 13$ had declined by more than $90 \%$ compared to 2005,5 where the prevalence had reduced by $73-88 \%$ and one (Sunuhu) where the prevalence in 2012/13 had decreased by only $28 \%$. These effects were quite similar for both $P$. falciparum and $P$. vivax, while in 1 village in 2012/13 no $P$. vivax infections were detected at all.

Parasite genetic complexity in 2005 compared to 2012/13 The majority of $P$. falciparum infections detected by LDRFMA in 2005 and qPCR in 2012/13 were successfully 
Table 3 Multivariable predictors of $P$. falciparum (A) and $P$. vivax (B) infections

\begin{tabular}{|c|c|c|c|c|c|c|c|c|}
\hline \multicolumn{9}{|c|}{ A. Predictors of $P$. falciparum infections } \\
\hline & \multicolumn{4}{|c|}{$2005(N=2486)$} & \multicolumn{4}{|c|}{$2012-2013(N=2370)$} \\
\hline & $\% \mathrm{Pf}$ & $\mathrm{aOR}$ & $95 \% \mathrm{Cl}$ & $p$-value & $\% \mathrm{Pf}$ & aOR & $95 \% \mathrm{Cl}$ & $p$-value \\
\hline Female & $55.5 \%$ & 1.0 & & 0.040 & & & & \\
\hline Male & $57.3 \%$ & 1.2 & {$[1.01-1.4]$} & & & & & \\
\hline Anaemia & & & & $<0.001$ & & & & 0.0029 \\
\hline No & $49.3 \%$ & 1.0 & & & $3.8 \%$ & 1.0 & & \\
\hline Mild & $51.2 \%$ & 1.2 & {$[0.95-1.6]$} & & $5.0 \%$ & 1.1 & {$[0.6-2.0]$} & \\
\hline Moderate & $60.0 \%$ & 1.8 & {$[1.4-2.3]$} & & $12.0 \%$ & 1.9 & {$[1.1-3.2]$} & \\
\hline Severe & $71.7 \%$ & 3.4 & {$[2.0-5.6]$} & & $28.1 \%$ & 3.9 & {$[1.6-9.8]$} & \\
\hline Age group & & & & $<0.001$ & & & & 0.103 \\
\hline $0-3$ & $25.8 \%$ & 1.0 & & & $6.0 \%$ & 1.0 & & \\
\hline$>3-6$ & $44.4 \%$ & 2.9 & {$[1.8-4.4]$} & & $8.7 \%$ & 3.2 & {$[0.7-15.3]$} & \\
\hline$>6-9$ & $59.5 \%$ & 5.1 & {$[3.3-7.6]$} & & $12.0 \%$ & 4.6 & [1.0-22.0] & \\
\hline$>9-12$ & $70.2 \%$ & 8.2 & {$[5.2-12]$.} & & $10.7 \%$ & 4.1 & {$[0.9-19.6]$} & \\
\hline$>12-20$ & $73.6 \%$ & 12.9 & [8.3-19.] & & $9.2 \%$ & 7.1 & {$[1.5-34.5]$} & \\
\hline$>20$ & $54.1 \%$ & 4.7 & {$[3.1-6.8]$} & & $6.3 \%$ & 4.0 & [0.9-18.1] & \\
\hline \multicolumn{5}{|c|}{ Current or recent reported febrile illness } & & & & 0.0050 \\
\hline \multicolumn{5}{|c|}{ No } & $6.8 \%$ & 1.0 & & \\
\hline \multicolumn{5}{|c|}{ Yes } & $14.8 \%$ & 2.0 & {$[1.3-3.1]$} & \\
\hline \multicolumn{5}{|c|}{ P. vivax infected by qPCR } & & & & $<0.001$ \\
\hline \multicolumn{5}{|c|}{ No } & $5.6 \%$ & 1.0 & & \\
\hline \multicolumn{5}{|l|}{ Yes } & $48.1 \%$ & 5.6 & {$[3.4-9.1]$} & \\
\hline \multicolumn{4}{|l|}{ Village } & $<0.001$ & & & & $<0.001$ \\
\hline 5. Ilahita 3 & $57.4 \%$ & 1.0 & & & $2.1 \%$ & 1.0 & & \\
\hline 6. Ilahita 4 & $55.0 \%$ & 1.0 & {$[0.60-1.5]$} & & $3.0 \%$ & 1.4 & {$[0.3-6.0]$} & \\
\hline 7. Sunuhu & $81.9 \%$ & 3.8 & {$[2.2-6.2]$} & & $51.4 \%$ & 26.2 & [7.8-88.1] & \\
\hline 4. Urita & $61.0 \%$ & 1.1 & {$[0.71-1.8]$} & & $5.0 \%$ & 1.7 & [0.4-6.9] & \\
\hline 3. Salata & NA & & & & $6.1 \%$ & 2.7 & [0.7-9.9] & \\
\hline 2. Waragom & $68.6 \%$ & 1.6 & {$[0.97-2.5]$} & & $16.7 \%$ & 8.0 & [2.2-29.4] & \\
\hline 12. Jama & $38.8 \%$ & 0.4 & {$[0.2-0.6]$} & & $3.9 \%$ & 1.8 & {$[0.4-7.8]$} & \\
\hline 13. Sengo & $54.3 \%$ & 0.8 & {$[0.48-1.2]$} & & $7.5 \%$ & 4.2 & [1.2-14.5] & \\
\hline 14. Maiwi & $48.0 \%$ & 0.6 & {$[0.35-0.9]$} & & $13.4 \%$ & 6.6 & [1.7-25.8] & \\
\hline 15. Malba 1 & $49.7 \%$ & 0.7 & {$[0.47-1.1]$} & & $1.3 \%$ & 0.6 & {$[0.1-2.9]$} & \\
\hline 16. Malba 2 & $58.6 \%$ & 1.2 & [0.73-1.8] & & $3.6 \%$ & 2.2 & [0.6-8.6] & \\
\hline 17. Yenigo & $50.3 \%$ & 0.9 & {$[0.55-1.3]$} & & $0.6 \%$ & 0.4 & {$[0.0-3.7]$} & \\
\hline 10. Wapindumaka & NA & & & & $3.8 \%$ & 2.1 & {$[0.5-8.5]$} & \\
\hline 11. Wombisa & $53.5 \%$ & 0.8 & {$[0.51-1.3]$} & & $1.0 \%$ & 0.5 & [0.08-3.0] & \\
\hline 8. Wapin & $49.3 \%$ & 0.8 & {$[0.47-1.2]$} & & NA & & & \\
\hline 1. Bonohi & $56.4 \%$ & 1.1 & {$[0.68-1.7]$} & & NA & & & \\
\hline 9. Bangeleko & $59.5 \%$ & 1.0 & [0.63-1.6] & & NA & & & \\
\hline \multicolumn{9}{|c|}{ B. Predictors of $P$. vivax infections } \\
\hline & \multicolumn{4}{|c|}{$2005(N=2441)$} & \multicolumn{4}{|c|}{$2013(N=2324)$} \\
\hline & $\%$ & aOR & $95 \% \mathrm{Cl}$ & $p$ & $\%$ & $\mathrm{aOR}$ & $95 \% \mathrm{Cl}$ & $p$ \\
\hline \multicolumn{4}{|c|}{ Recent reported anti-malarial treatment } & $<0.001$ & & & & \\
\hline No & $38.3 \%$ & 1 & & & & & & \\
\hline Yes & $22.1 \%$ & 0.4 & {$[0.3-0.6]$} & & & & & \\
\hline
\end{tabular}


Table 3 (continued)

\begin{tabular}{|c|c|c|c|c|c|c|c|c|}
\hline \multicolumn{9}{|c|}{ B. Predictors of $P$. vivax infections } \\
\hline & \multicolumn{4}{|c|}{$2005(N=2441)$} & \multicolumn{4}{|c|}{$2013(N=2324)$} \\
\hline & $\%$ & aOR & $95 \% \mathrm{Cl}$ & $p$ & $\%$ & aOR & $95 \% \mathrm{Cl}$ & $p$ \\
\hline \multicolumn{4}{|c|}{ Current or recent reported febrile illness } & 0.006 & & & & \\
\hline No & $37.9 \%$ & 1.0 & & & & & & \\
\hline Yes & $25.6 \%$ & 0.6 & {$[0.4-0.9]$} & & & & & \\
\hline Female & $34.8 \%$ & 1.0 & & 0.077 & & & & \\
\hline Male & $39.5 \%$ & 1.2 & {$[0.98-1.4]$} & & & & & \\
\hline Age group & & & & $<0.001$ & & & & 0.0030 \\
\hline $0-3$ & $24.3 \%$ & 1.0 & & & $6.5 \%$ & 1.0 & & \\
\hline$>3-6$ & $49.0 \%$ & 3.0 & {$[1.9-4.7]$} & & $7.5 \%$ & 1.4 & {$[0.3-5.8]$} & \\
\hline$>6-9$ & $48.7 \%$ & 2.8 & {$[1.9-4.3]$} & & $10.7 \%$ & 2.2 & {$[0.5-9.1]$} & \\
\hline$>9-12$ & $53.1 \%$ & 3.4 & {$[2.2-5.3]$} & & $11.7 \%$ & 2.8 & {$[0.7-11.8]$} & \\
\hline$>12-20$ & $37.1 \%$ & 1.7 & {$[1.1-2.6]$} & & $5.8 \%$ & 1.3 & {$[0.3-5.2]$} & \\
\hline$>20$ & $29.7 \%$ & 1.1 & {$[0.8-1.7]$} & & $3.8 \%$ & 0.9 & {$[0.2-3.7]$} & \\
\hline \multicolumn{4}{|c|}{ P. falciparum infected by qPCR } & & & & & $<0.001$ \\
\hline \multicolumn{4}{|c|}{ No } & & $3.3 \%$ & 1.0 & & \\
\hline \multicolumn{4}{|l|}{ Yes } & & $32.7 \%$ & 4.9 & {$[3.1-7.8]$} & \\
\hline \multicolumn{4}{|l|}{ Village } & 0.0012 & & & & $<0.001$ \\
\hline 5. Ilahita 3 & $38.6 \%$ & 1.0 & & & $2.1 \%$ & 1.0 & & \\
\hline 6. Ilahita 4 & $37.8 \%$ & 1.1 & {$[0.7-1.7]$} & & $2.4 \%$ & 1.1 & {$[0.2-5.1]$} & \\
\hline 7. Sunuhu & $40.3 \%$ & 1.1 & {$[0.7-1.8]$} & & $36.0 \%$ & 11.9 & {$[3.5-40.4]$} & \\
\hline 4. Urita & $46.9 \%$ & 1.3 & {$[0.8-2.1]$} & & $9.0 \%$ & 4.2 & [1.2-14.9] & \\
\hline 3. Salata & NA & & & & $5.3 \%$ & 2.4 & {$[0.7-8.6]$} & \\
\hline 2. Waragom & $42.0 \%$ & 1.1 & {$[0.7-1.7]$} & & $8.4 \%$ & 3.5 & [0.9-13.7] & \\
\hline 12. Jama & $29.1 \%$ & 0.6 & [0.4-1.0] & & $3.1 \%$ & 1.3 & {$[0.3-6.1]$} & \\
\hline 13. Sengo & $26.2 \%$ & 0.5 & {$[0.3-0.8]$} & & $4.4 \%$ & 1.8 & {$[0.5-6.3]$} & \\
\hline 14. Maiwi & $36.4 \%$ & 0.8 & {$[0.5-1.3]$} & & $2.9 \%$ & 0.9 & {$[0.1-5.4]$} & \\
\hline 15. Malba 1 & $44.9 \%$ & 1.2 & [0.7-1.9] & & $1.6 \%$ & 0.7 & {$[0.2-3.4]$} & \\
\hline 16. Malba 2 & $42.2 \%$ & 1.1 & {$[0.7-1.8]$} & & $1.7 \%$ & 0.7 & {$[0.1-3.4]$} & \\
\hline 17. Yenigo & $36.9 \%$ & 0.9 & {$[0.5-1.4]$} & & NA & & & \\
\hline 10. Wapindumaka & NA & & & & $0.5 \%$ & 0.2 & {$[0.02-2.0]$} & \\
\hline 11. Wombisa & $34.9 \%$ & 0.8 & {$[0.5-1.3]$} & & $0.5 \%$ & 0.2 & {$[0.02-2.3]$} & \\
\hline 8. Wapin & $29.9 \%$ & 0.6 & {$[0.4-1.1]$} & & NA & & & \\
\hline 1. Bonohi & $34.7 \%$ & 0.8 & {$[0.5-1.3]$} & & NA & & & \\
\hline 9. Bangeleko & $33.1 \%$ & 0.7 & {$[0.4-1.1]$} & & NA & & & \\
\hline
\end{tabular}

\% indicate proportion infected with P. falciparum or P. vivax detected by LDR-FMA (2005) or qPCR (2013) and/or LM within the designated group $a O R$ multivariable adjusted odds ratio, $\mathrm{Cl}$ confidence interval

Italics $p$-values are considered statistically significant $(p<0.05)$

genotyped (63.0\% and $77.8 \%$, respectively). Similarly, $P$. vivax infections were successfully genotyped by at least one of two markers Pvmsp1f3 and PvMS2 (63.5\% in 2005 and $64.7 \%$ 2012/13). The total number of different alleles detected by the markers was lower in 2012/13 than in 2005, but the most common alleles were similar between the 2 years (Additional file 3). The mean multiplicity of infection (MOI) decreased from 1.8 to 1.6 for P. falcipa$\operatorname{rum}(\mathrm{p}=0.08$, Mann-Whitney U test) and from 2.2 to 1.4 for P. vivax ( $\mathrm{p}<0.001$, Mann-Whitney U test). However, the proportion of $P$. falciparum multiple clone infections (MOI $>1)$ remained constant $(45.4 \%$ in 2005 vs $42.4 \%$ in 2012/13; $\mathrm{p}=0.478, \mathrm{X}^{2}$ ), while the proportion of $P$. vivax multiple clone infections decreased from $58.2 \%$ in 2005 to $31.1 \%$ in $2012 / 13\left(\mathrm{p}<0.001, \mathrm{X}^{2}\right)$. In addition, $54 \%$ of P. vivax single clone infections were sub-microscopic in 2012/13, and MOI was significantly associated with submicroscopic $P$. vivax infections in both years $(\mathrm{p}<0.001$, 


\section{5}
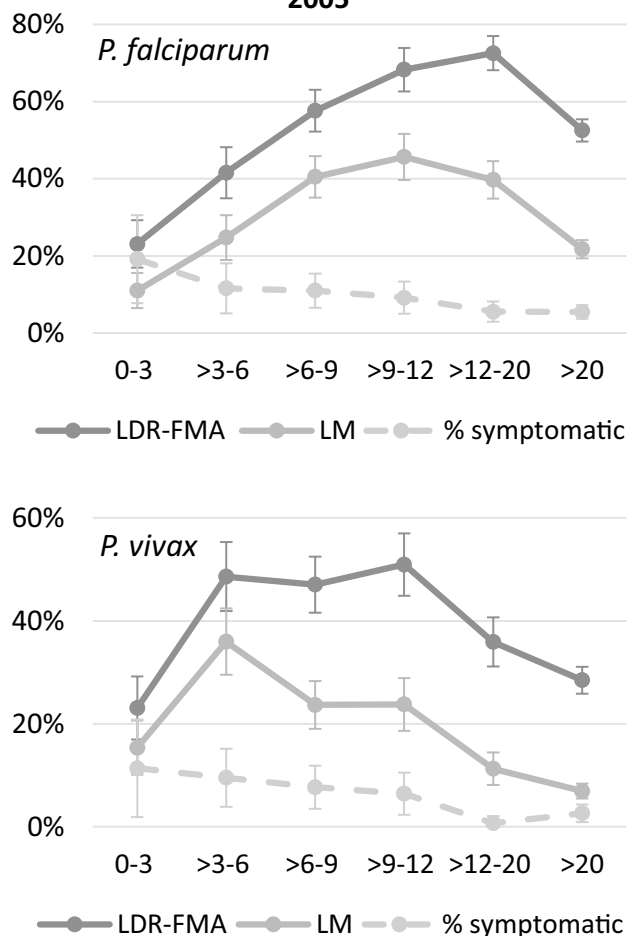

$30 \%$

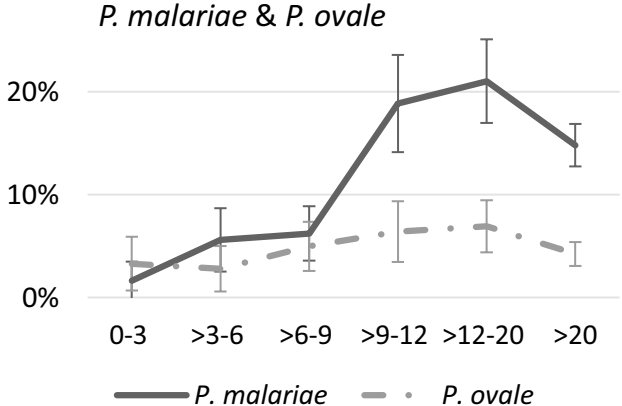

2012-13
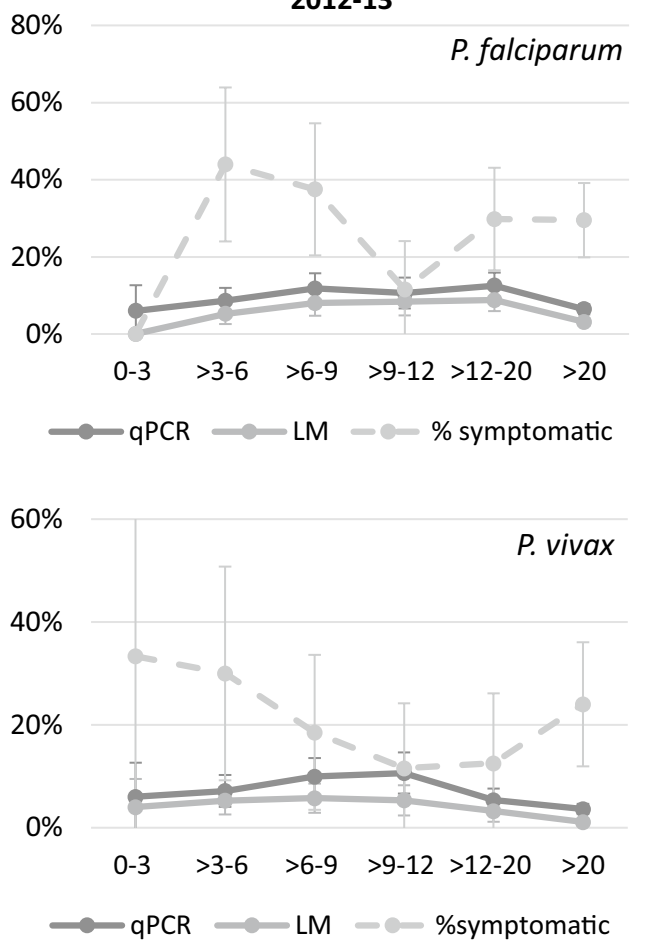

$30 \%$

P. malariae \& P. ovale

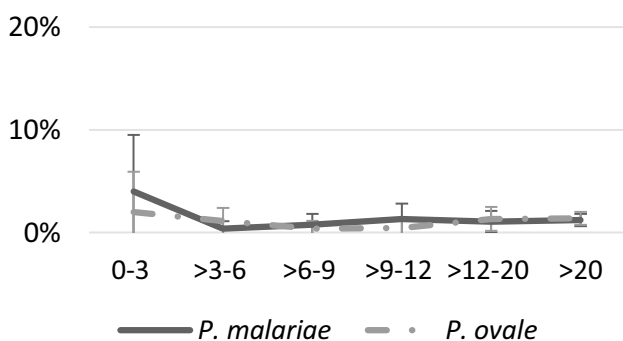

Fig. 1 Age distributions of malaria prevalence. Top 4 panels: $P$. falciparum or $P$. vivax prevalence by LDR-FMA or qPCR, prevalence by light microscopy and proportion symptomatic $P$. falciparum or $P$. vivax infections. Bottom panels: prevalence of $P$. malariae and $P$. ovale. Error bars represent 95\% confidence intervals. Left 2005 survey, right 2012/13 survey

logistic regression). Despite the significant decrease in prevalence, the overall genetic diversity $(\mathrm{He})$ was high in both years for both species (Table 4). Despite large differences in prevalence in 2012-2013, MOI and He were very similar across catchment areas (Table 4) and villages, and diversity seemed lowest in the highest prevalence area.

In both years, the majority of $P$. falciparum infections in individuals over 12 years were single clone infections, whereas between the ages of 3 to 12 years more multiple clone infections were found (Fig. 3a). Single clone $P$. vivax infections were similarly distributed between all age groups in 2005, however, in 2012/13, there was a significantly higher proportion of $P$. vivax single clone infections in ages above 9 years (Fig. 3b). The proportion of multiple clone $P$. falciparum and $P$. vivax infections are quite evenly distributed in the different areas, despite differences in prevalence between the villages in both years (Figs. 3c, d).

\section{Heterogeneity of infection at the household level}

Overall, considerably fewer households were affected by malaria infections in 2012/13 than in 2005. In 2005, $96.5 \%$ of all households had 1 or more individuals with an infection (detected by LM and/or MM), while in 


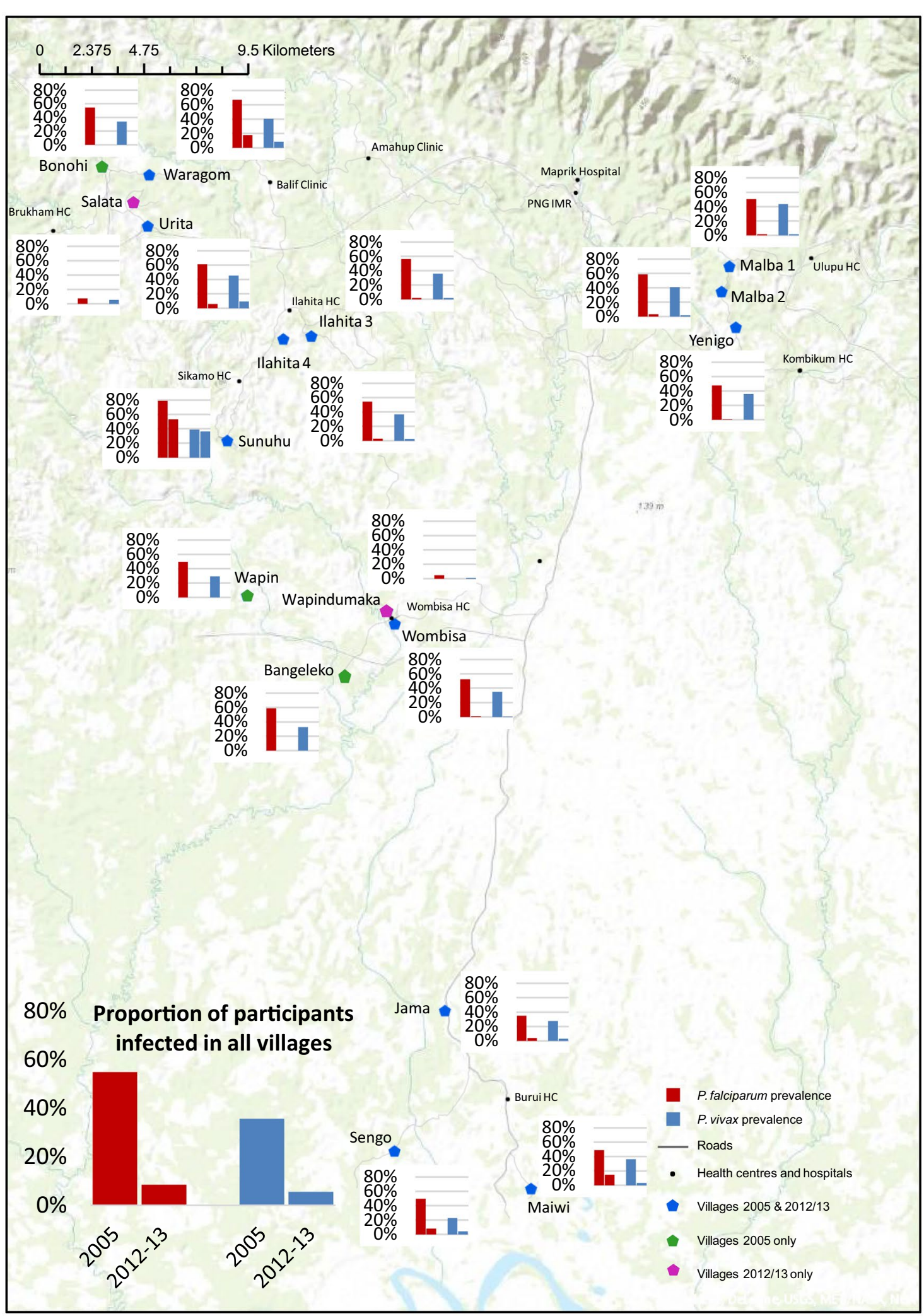

Fig. 2 Map of study area with village-specific malaria prevalence in 2005 and 2013. Red bars indicate $P$. falciparum prevalence and blue bars $P$. vivax prevalence. Villages with a blue symbol (pentagon) were included in both surveys, villages with a green symbol were included in the 2005 survey only and villages with a purple symbol were included in the 2012-2013 survey only 
Table 4 Genetic diversity, prevalence and multiplicity of infection of $P$. falciparum and $P$. vivax infections at the health centre catchment area level

\begin{tabular}{|c|c|c|c|c|c|c|}
\hline & \multicolumn{3}{|l|}{2005} & \multicolumn{3}{|l|}{$2012 / 13$} \\
\hline & Prevalence (\%) & MOI & $\mathrm{He}$ & Prevalence & MOI & $\mathrm{He}$ \\
\hline \multicolumn{7}{|l|}{ Pfmsp2 } \\
\hline Overall & 54.9 & 1.8 & 0.94 & 8.5 & 1.6 & 0.91 \\
\hline Ilahita & 63.8 & 2.2 & 0.93 & 21.6 & 1.6 & 0.88 \\
\hline Brukham & 60.8 & 1.9 & 0.94 & 8.8 & 1.4 & 0.93 \\
\hline Burui & 43.4 & 1.4 & 0.95 & 7.9 & 1.5 & 0.94 \\
\hline Ulupu & 52.2 & 1.7 & 0.92 & 1.9 & 1.5 & 0.97 \\
\hline Wombisa & 53.8 & 1.7 & 0.94 & 2.5 & 1.6 & 0.83 \\
\hline \multicolumn{7}{|l|}{ Pvmsplf3 } \\
\hline Overall & 35.7 & 2.1 & 0.89 & 5.6 & 1.4 & 0.90 \\
\hline Ilahita & 37.2 & 2.7 & 0.91 & 15.0 & 1.4 & 0.85 \\
\hline Brukham & 39.8 & 2.3 & 0.92 & 7.2 & 1.3 & 0.92 \\
\hline Burui & 28.4 & 1.6 & 0.88 & 3.8 & 1.3 & 0.94 \\
\hline Ulupu & 39.9 & 2.1 & 0.88 & 1.2 & 1 & \\
\hline Wombisa & 32.4 & 1.9 & 0.88 & 0.5 & $\mathrm{~N} / \mathrm{A}$ & \\
\hline \multicolumn{7}{|l|}{ PvMS2 } \\
\hline Overall & 35.7 & 1.8 & 0.91 & 5.6 & 1.3 & 0.90 \\
\hline Ilahita & 37.2 & 2.3 & 0.91 & 15.0 & 1.2 & 0.91 \\
\hline Brukham & 39.8 & 1.8 & 0.91 & 7.2 & 1.2 & 0.92 \\
\hline Burui & 28.4 & 1.7 & 0.93 & 3.8 & 1.4 & 0.87 \\
\hline Ulupu & 39.9 & 1.8 & 0.91 & 1.2 & 1.8 & \\
\hline Wombisa & 32.4 & 1.6 & 0.91 & 0.5 & N/A & \\
\hline
\end{tabular}

MOI mean multiplicity of infection, He expected heterozygosity. Diversity calculation for $P$. vivax in Ulupu in 2012-2013 was not calculated due to small sample size

2012-2013 only $27.8 \%$ of households had an individual with a LM and/or MM-detectable infection $\left(x^{2} p<0.001\right)$. As expected, the proportion of households that were infected in 2012-2013 was highest in villages with relatively higher prevalence of infection. In 2005, the majority of households had 2 or more individuals infected (81.1\% of all infected households), whereas in 2012-2013, the majority of infected households had only 1 individual infected (61.7\% of infected households) (Fig. 1). Although self-reported LLIN/bed net ownership or use was not a significant predictor of malaria infection or illness at the individual level, household-stratified analysis revealed that a higher prevalence of malaria in a village (any species by LM and/or PCR) was significantly associated with lower proportion of self-reported bed net/LLIN use in the household in both years $(\mathrm{p} \leq 0.004$, linear regression corrected for mean age).

In $2005,76.4 \%$ of the infected households were highinfection rate household (more than $50 \%$ of individuals in the household infected), whereas in 2012-2013, this had decreased to $27.6 \%$ ( $p>0.001)$ and the proportion of high-infection rate households (of all infected households) was associated with prevalence in the village in both years (linear regression, $\mathrm{p}<0.001$ ). A higher proportion of reported bed net use in the household was associated with a reduced risk of the household being a high rate household in 2005 (Table 4), but not in 20122013 when reported LLIN use was very high $(95 \%$, see Additional file 2). Predictors of high-infection rate households in 2012/13 were households with the presence of clinical cases, microscopic infections and/or gametocyte carriers (Table 5).

\section{Discussion}

In the historically high transmission region of ESP in PNG, a dramatic change in the burden and epidemiology of malaria was observed over the period of time coinciding with the scale-up of control via nationwide LLIN distributions and strengthening of malaria diagnosis and treatment at peripheral health facilities. Overall Plasmodium prevalence as detected by LM and/or MMs has declined from $74.2 \%$ in 2005 to $12.8 \%$ in $2012 / 13$, a substantially sharper decline than has been observed in another study area along the North Coast of Papua New Guinea [36]. Alongside the reduction in prevalence and complexity of infections, a shift towards a more uniform distribution of infections and illness across age groups 


\section{a P. falciparum}
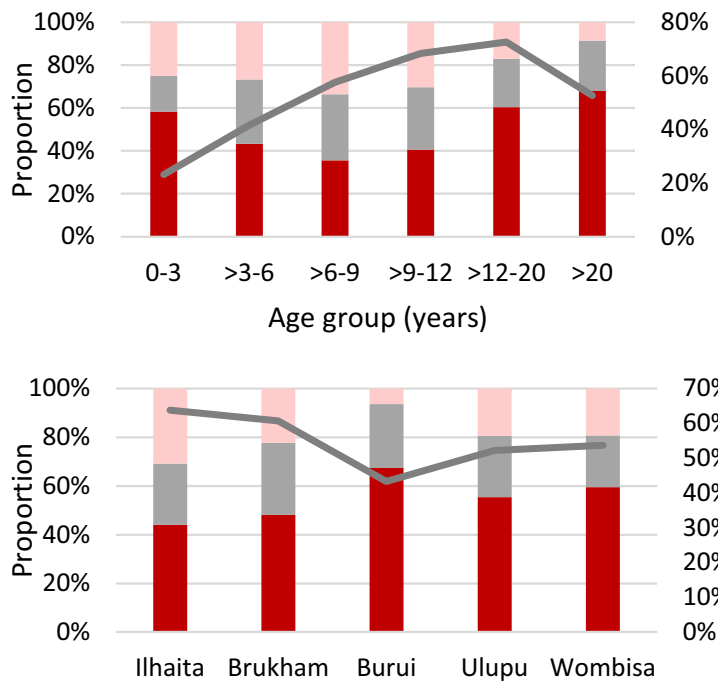
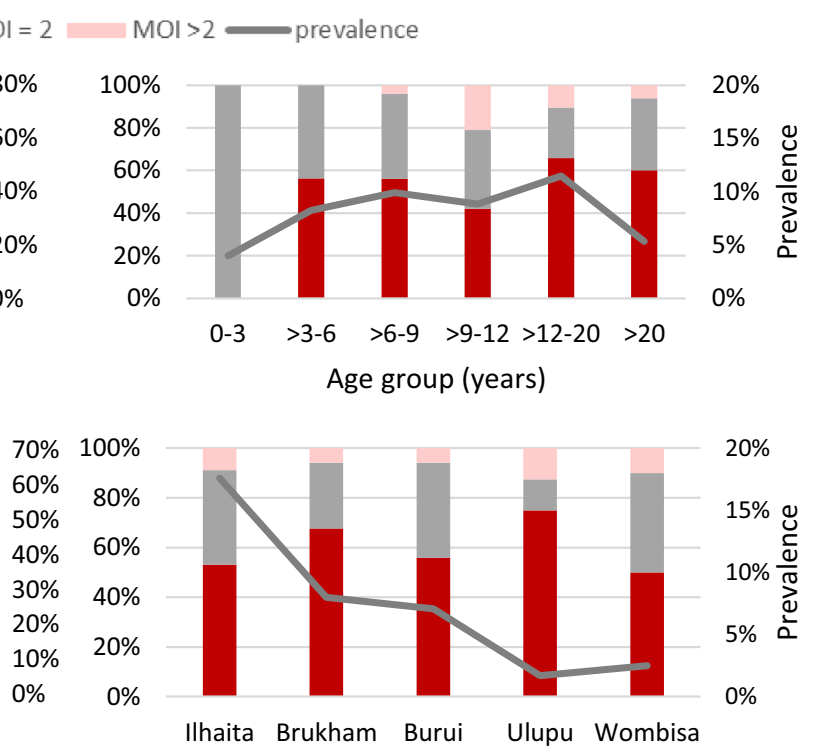

\section{b P. vivax}
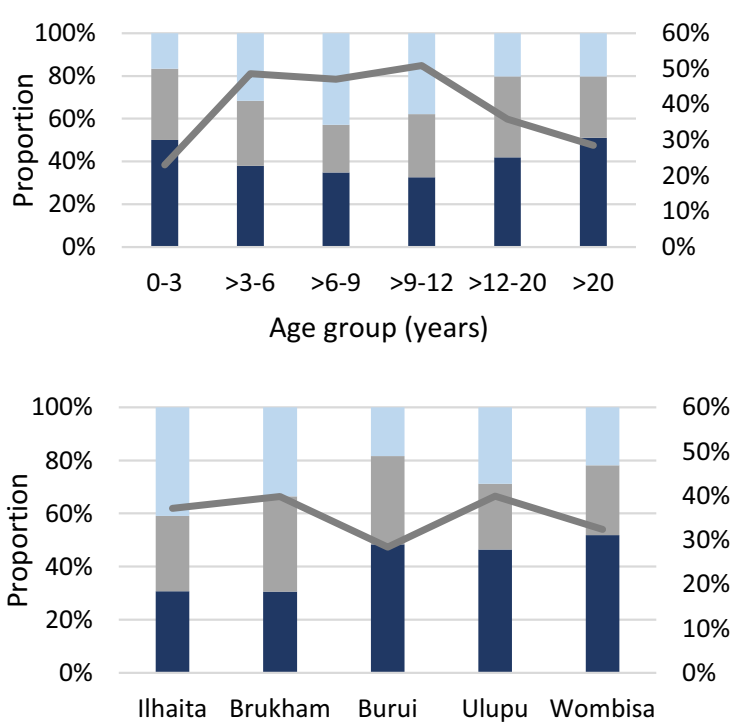

2005

$60 \%$
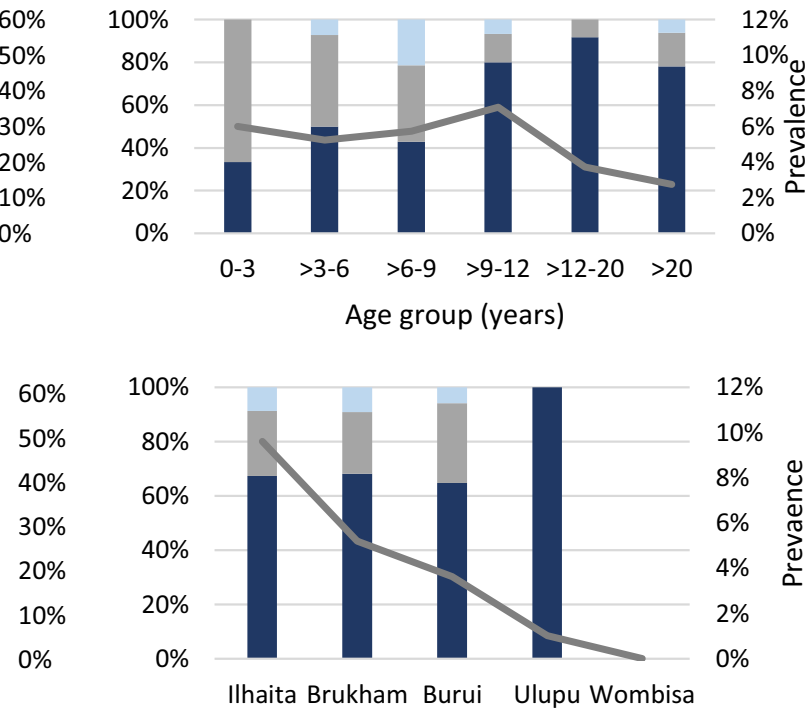

$2012 / 13$

Fig. 3 Proportion of single and multiple clone $P$. falciparum and $P$. vivax infections. a $P$. falciparum infection by age group and catchment area; $\mathbf{b} P$. vivax infection by age group and catchment area; Left 2005, right 2012/13. Red/grey: P. falciparum, Blue/grey: P. vivax. MOI multiplicity of infection

but greater heterogeneity in transmission across the study area and within the study villages was observed.

Heterogeneity in malaria prevalence between villages is not a new phenomenon [3, 4, 37-39]. In the 2012-2013 study, transmission in some villages had not declined as much as in others, increasing this difference between and within villages. In those areas with higher prevalence, reported use of LLINs was lower and anaemia and fever were more prevalent. While coverage of bed nets was already high in this area in 2005 (88.3\%), the majority of nets at that time were untreated nets, whereas in 20122013 most people should have had access to LLINs, and 
Table 5 Multivariable predictors of households with high proportion of household members with MM-detectable infections ( $>50 \%)$, adjusted for mean age in the household

\begin{tabular}{|c|c|c|c|}
\hline \multicolumn{4}{|c|}{ Predictors of households with a high proportion of MM-detectable infections } \\
\hline $2005(\mathrm{Nhh}=659)$ & aOR & {$[95 \% \mathrm{Cl}]$} & $p$-value \\
\hline Proportion of hh members reporting use of bed net & 0.4 & {$[0.2-0.8]$} & 0.012 \\
\hline Moderate or severe anaemia in the hh & 1.0 & {$[0.6-1.7]$} & 0.95 \\
\hline Microscopic infections in the hh & 5.9 & {$[3.8-9.1]$} & $<0.001$ \\
\hline Gametocyte carrier (by LM) in the hh & 3.7 & {$[1.4-9.4]$} & 0.007 \\
\hline $2012-2013(\mathrm{Nhh}=430)$ & aOR & {$[95 \% \mathrm{Cl}]$} & $p$-value \\
\hline Clinical case in the hh & 2.6 & {$[1.0-6.9]$} & 0.05 \\
\hline Microscopic infections in the hh & 4.8 & {$[1.4-16.4]$} & 0.012 \\
\hline Gametocyte carrier (by LM) in the hh & 3.8 & {$[1.4-10.6]$} & 0.011 \\
\hline Ilhaita_4 (reference) & 1.0 & & \\
\hline Sunuhu & 34.9 & {$[4.1-299.3]$} & 0.001 \\
\hline Urita & 1.7 & {$[0.1-30.1]$} & 0.733 \\
\hline Salata & 7.2 & {$[0.8-65.5]$} & 0.078 \\
\hline Waragom & 4.3 & {$[0.4-51.2]$} & 0.246 \\
\hline Jama & 1.7 & {$[0.1-30.2]$} & 0.725 \\
\hline Sengo & 1.8 & {$[0.2-19.5]$} & 0.610 \\
\hline Maiwi & 7.7 & {$[0.6-107.8]$} & 0.129 \\
\hline Ilhaita_3 & No high rate households & & \\
\hline Malba_1 & No high rate households & & \\
\hline Malba_2 & No high rate households & & \\
\hline Yenigo & No high rate households & & \\
\hline Wapindumaka & No high rate households & & \\
\hline Wombisa & No high rate households & & \\
\hline
\end{tabular}

$\mathrm{Cl}$ confidence interval, $h$ h household, $L M$ light microscopy, $M M$ molecular method, Wh number of households

Italics $p$-values are considered statistically significant $(p<0.05)$

questions specified LLINs. In the village with the highest prevalence, Sunuhu, LLIN use was lowest, which could be a major factor contributing to the high level of transmission in that village. The use of insecticide-treated nets (ITNs) has been shown in many studies to be effective in reducing mortality and morbidity from malaria [40-42]. In addition, it is thought that use of ITNs leads to community-level effects, where the majority of the population (even those not using ITNs) are protected when ITN coverage in the community is high, due to reduction in the number of infected mosquitoes and mosquito survival [43-46]. This effect has, however, not been well quantified and impact of LLINs varies with the coverage rate. In addition, the required coverage might be different for different areas, depending on local factors such as the anopheline density, species composition and both vector and human behaviour [47].

Renewed political and financial will to strengthen malaria control at the beginning of the millennium, resulted in the PNG National Department of Health launching a new campaign to quickly achieve high levels of LLIN ownership and usage. Nationwide free LLIN distribution took place between 2004 and 2009 and resulted in a significant increase in ownership of bed nets (any type 80.1\%; LLINs 64.6\%) [20]. Despite this increase, reported LLIN use remained low (32.5\%), and the majority of people not using nets reported not having access to (unoccupied) nets [20]. A second round of country-wide LLIN distribution was conducted between 2010 and 2014 to cover the gaps in mosquito net coverage [21]. LLINs in the study area in ESP were distributed 12 months prior to this 2012/13 survey (September 2011 and October 2012) and a new round of LLIN distribution occurred in 2014/2015 (personal communication, NMCP/Rotarians Against Malaria). Large-scale LLIN distribution campaigns were performed in ESP earlier than in many other provinces with a high malaria burden, and LLIN coverage in ESP seems to be higher than on the North Coast area in general [21,36], likely due to a higher density of nuisance biters encouraging greater use of LLINs. The substantial impact of LLINs on transmission in this area might also be due to the fact that transmission in ESP is 
predominantly driven by $A n$. punctulatus, which feeds later at night (after midnight/early morning) and equally indoors and outdoors, making it highly susceptible to LLINs. A recent study reported an increase in prevalence of An. punctulatus and a decrease of An. koliensis, another late biter, in an adjacent area in East Sepik province, as well as a shift to earlier mean biting times of $A n$. punctulatus in addition to significantly reduced manbiting-rates and annual entomological inoculation rates after the LLIN campaign [48]. Proximity to vector-breeding sites is related to the risk of malaria and can also be a main driver of heterogeneity [49-51], but was not investigated in the current study.

Cultural factors, socio-economic status and education level play an additional role in risk of infection and can vary across villages and households, as well as human behavioural and genetic factors $[9,21,28,52-56]$. The time and manner of LLIN distribution in these areas can play a role in their availability, use and quality/age of the LLIN. For example, in some areas the LLINs might have been distributed directly to each household, whereas in other areas, people will have gone to their local health centres to obtain their LLINs. There are also real or perceived differences in the availability of RDTs, effective anti-malarials and quality of care received at the health centres [19]. In Sunuhu, for example, the population is of a different ethnic origin than surrounding villages, more closely related to the population in Gwanga local level government (LLG) than Ilahita LLG. The Sunuhu population have less material wealth, less access to nutritious food, and rates of malnutrition and generally poor health are more common than in neighbouring villages. They may also be less likely to access care at the nearby health centre (due to distance, cultural difference, perceived benefit) and it is possible their access to LLINs has been reduced as a result.

Despite the decrease in prevalence and significant geographic heterogeneity, the genetic diversity of both $P$. falciparum and $P$. vivax appears to have been maintained at relatively high levels. Multiplicity of infection and especially the proportion of multiple clone infections has decreased. The proportion of multiple clone infections correlated well with prevalence and might be a suitable indicator of hotspot areas and areas of high transmission. Further investigation of markers that are not under selective pressure is required for a more detailed analysis of the impact of malaria control on genetic diversity, differentiation and population structure in this area $[57,58]$.

Although the prevalence of malaria has decreased across all age groups and there is no marked shift in the peak age of infections (compared to the 2005 survey and others [5]), there is a relatively higher proportion of symptomatic infections in the 2012/13 survey). This, together with a five- to ninefold increase in the proportion of symptomatic infections in adults is an indication that there might be reduced or delayed acquisition of immunity. More detailed investigations on the effect of the decreased transmission intensity on the incidence (and complexity) of malaria infections and clinical malaria episodes, and age/exposure related acquisition of clinical immunity are being conducted in several longitudinal child cohorts in East Sepik and Madang Province.

The impact on the prevalence of $P$. vivax was similar or higher as on P. falciparum, in 10 of 12 villages surveyed in both years. Based on the biology of relapsing $P$. vivax infections from hypnozoites and the fact that neither LLINs nor ACTs act to prevent these relapsing infections it is generally thought that $P$. vivax burden is more resilient to these tools and that an equivalent impact may not be observed in the same timeframe as for P. falciparum. In the same area as this study, a series of cohort studies showed that while $P$. vivax clinical episodes declined at rates comparable to $P$. falciparum, force of blood stage infections and prevalence took longer to decline [59]. The data presented here suggest that 8 years post-scaleup of LLINs appears to be a sufficient length of time for the hypnozoite burden to have been exhausted in most villages.

Although the two studies were not conducted at the same time of the year (April-May in 2005 vs. Oct-Feb in 2012-2013), this difference in timing is unlikely to substantially contribute to the observed decrease in prevalence between surveys. The 'wet' season is usually from October-April, whereas the so-called 'dry' season runs from May-September, however, in most parts of the lowlands of PNG there is perennial malaria transmission, with limited seasonality $[2,4,8]$. Previous repeated cross-sectional surveys in the neighbouring Wosera area showed no clear-cut seasonal patterns $[3,5]$ and a detailed paediatric longitudinal cohort showed increased transmission during the rainy season $[60,61]$. In addition, a substantial decline in infection prevalence and clinical malaria episodes was also observed in three longitudinal child cohort studies conducted in the same area spanning a similar time period [59].

A limitation of the study was that the MM used to detect infections in the two time-periods was not the same. However, a previous study directly comparing qPCR and LDR-FMA reported substantial agreement between the two methods [32]. While the LDR-FMA detected slightly higher numbers of $P$. falciparum infections in that study (47\% vs 41\%) [32], this is not sufficient to be responsible for the observed difference in prevalence between the two studies, which mirrors the drop in prevalence by LM. The decreased prevalence of submicroscopic $P$. falciparum and $P$. vivax infections in the 
$2012 / 13$ study is potentially influenced by the difference between qPCR and LDR-FMA and thus the data from this earlier survey will appear to have a slightly higher proportion of sub-microscopic infections than when qPCR was used. In addition, 2nd reads of microscopy slides in 2012-2013 were performed based on qPCR results, potentially resulting in a lower proportion of submicroscopic infection.

This study was not a formal component of the monitoring and evaluation of the national malaria control programme, with the primary aim to delve into the impact that reduced transmission is having on the epidemiology of malaria rather than assess the programme itself. Prevalence reported in this study is much higher than provincial averages from the national reports $[22,62]$, which to a large extent can be explained by the higher sensitivity of the MM that were used in these studies as compared to microscopy and RDTs. Molecular tools are much more sensitive at detecting low levels of parasitaemia and are therefore crucial to get a detailed insight on the prevalence of not only clinical disease, but also asymptomatic reservoirs of infection. Microscopic infections in the household, as well as gametocyte carriers were associated with high rate infection households in both years and in 2012-2013 many high rate households contained clinical cases, highlighting the utility of clinical and microscopy-based surveillance to identify transmission foci that could be specifically targeted with interventions aimed at reducing not only clinical cases, but the asymptomatic reservoir as well. Although the national programme is very effective in determining the impact on a national level, this study facilitates the investigation at a different level of sensitivity, geographical scale and subsequent detection of fine-scale heterogeneity in transmission.

Identifying and targeting focal points and hotspots of malaria is highly relevant for malaria control, since these are likely to be the areas where residual malaria transmission will persist, and can become an obstacle in efforts to eliminate malaria $[28,63,64]$. In addition they can play a catalysing role: hotspots fuel transmission within transmission foci, and interventions targeted at transmission hotspots therefore have the potential to reduce community-wide malaria transmission [28, 64]. Many of the high burden villages found in 2012/13 were also areas of the highest prevalence in 2005, and it remains to be seen if these same areas are still high in prevalence in future. If these hot spots are consistently at the same location, implementation of control tools to target them will be much easier. In other regions in the world, it has been observed that hotspots are remarkably stable even when transmission intensity declines, although clinical incidence might vary with time [28, 65-67]. In addition to scaling up conventional vector control tools such as LLINs and indoor residual spraying in these hotspot areas, other tools could be implemented that might prove more useful in these particular areas. Ongoing entomological studies in East Sepik and Madang provinces may advise on the suitability of additional vector control tools. Alternatively targeting the parasite via interventions to reduce the infectious reservoir in these communities, such as mass screening and treatment (MSAT) and mass drug administration (MDA). Modelling has shown that MDA targeting blood and liver stage drugs might be more effective in reducing $P$. falciparum and $P$. vivax prevalence than MSAT [68] and implementation of such strategies may be feasible to achieve in these relatively small communities.

\section{Conclusions}

Although Papua New Guinea's strengthened malaria control programme successfully reduced malaria prevalence nationwide between 2005 and 2013, with a substantial impact in ESP, areas with high ongoing transmission remain. In this study, LLIN coverage and use, socioeconomic factors, vector density/behaviour and environmental factors are the likely drivers of this heterogeneity and resilience in the face of control. In order to further reduce transmission in these areas, additional surveillance approaches, novel tools and community engagement strategies may need to be layered on top of sustained nationwide LLIN coverage and effective case management.

\section{Supplementary information}

Supplementary information accompanies this paper at https://doi. org/10.1186/s12936-020-03265-x.

Additional file 1. Definition of anaemia. Definitions of anaemia that were used in the analyses stratified by age and sex. Values represent haemoglobin levels in $\mathrm{g} / \mathrm{L}$. Adapted from [35].

Additional file 2. Detailed demographic and clinical characteristics of study participants. Additional participants characteristics to Table 1.

Additional file 3. Allele frequencies of Pfmsp 1, Pvmsp 1f3 and PvMS2 alleles in both surveys. Allele frequencies A) Pfmsp 1 alleles in 2005 (top) vs 2012/13 (bottom) of all alleles (left) and split into 3D7 (centre) and FC27 (right) allele families, and B) Pvmsp 1f3 and PvMS2 in 2005 (top) vs 2012/13 (bottom).

\section{Abbreviations}

ACT: Artemisinin combination therapy; AIC: Akaike information criterion; aOR: Adjusted odds ratio; Cl: 95\% confidence interval; ESP: East Sepik Province, PNG; He: Expected heterogeneity; ITN: Insecticide treated net; LDR-FMA: Ligase detection reaction/microsphere assay; LLIN: Long-lasting insecticide net; LLG: Local level government; LM: Light microscopy; MDA: Mass drug administration; MFI: Median fluorescent intensity (from LDR-FMA); MOI: Multiplicity of infection; MM: Molecular method, i.e. qPCR and/or LDR-FMA; MSAT: Mass screening and treatment; NMCP: PNG national malaria control programme; Pfmsp2: P. falciparum merozoite surface protein 2; PCR: Polymerase chain reaction; PNG: Papua New Guinea; PvMS2: P. vivax microsatellite marker 2; 
Pvmsp1f3: P. vivax merozoite surface protein 1-f3 region; QMAL: Generic Pan Plasmodium PCR; qPCR: Quantitative PCR (real time PCR), in particular here this means the $18 \mathrm{~S}$ rRNA detecting species specific qPCR; qRT-PCR: Reverse transcriptase PCR, in particular here this means the Pfs 25 and Pvs 25 qRT-PCR for gametocyte detection; RDT: Rapid diagnostic test; WBC: White blood cell.

\section{Acknowledgements}

We wish to sincerely thank all members of the communities that participated in the surveys. We thank PNGIMR microscopy, laboratory, field and administration staff for their contributions that made the collection of this data possible.

\section{Authors' contributors}

JHK compiled the data, performed the analyses and was a major contributor to writing the manuscript, and coordinated and analysed the molecular laboratory experiments (extractions, qPCRs, qRT-PCRs, genotyping). DLN performed and analysed genotyping for the 2005 survey and contributed to writing the manuscript. MOK coordinated the field study in 2012-2013, coordinated data-entry and cleaning, and contributed to writing the manuscript. SK advised JHK regarding statistics analysis, mapping and contributed to writing the manuscript. BK and MP were responsible for the day-to-day on-site management of sample collections in the field. SJ and BK performed the extractions and qPCRs and qRT-PCRs for the 2012-2013 survey. NS was the microscopist responsible for reading of slides in the 2012-2013 study. LJR IM JK IF AEB and PMS conceived the ideas for the studies. LJR, IF and IM were major contributors to the manuscript and analysis plans. IM was responsible for the overall oversight and management of the 2005 study. LJR was responsible for the overall oversight and management of the 2012-2013 study. All authors read and approved the final manuscript.

\section{Funding}

This work was funded by NIH NIAID International Centres of Excellence in Malaria Research (ICEMR) South West Pacific (U19 Al089686), Bill \& Melinda Gates Foundation TransEPI grant, NIH NIAD International Centres of Excellence in Malaria Research (ICEMR) Asia Pacific (U19 Al129392-01) and NHMRC Programme Grant (GNT 1092789). IM is supported by NHMRC Principal Research Fellowship (GNT11155075) and LJR was supported by NHMRC Early Career Fellowship (GNT1016443) and is currently supported by NHMRC Career Development Research Fellowship (GNT1161627).

\section{Availability of data and materials}

The datasets generated during and/or analysed during the current study are not publicly available because it would compromise participant confidentiality and violates the ethical agreement in the informed consent forms. Data are however available upon reasonable request by contacting the PNG Medical Research Advisory Committee and the PNG Institute of Medical Research IRB. Please contact the corresponding author if you wish to access the data.

\section{Ethics approval and consent to participate}

Written informed consent was obtained from all study participants or their parents or legal guardians. The studies were approved by PNG IMR IRB and the PNG Medical Research Advisory Committee (MRAC 00.26 \& 05.20 \& 12.06), National Institutes of Health, Division of Microbiology and Infectious Diseases (DMID Protocol \#10-0035) and University Hospital Cleveland IRB. The 2012/2013 study was also reviewed and approved by the WEHI Human Research Ethics Committee.

\section{Consent for publication}

Not applicable.

\section{Competing interests}

The authors declare that they have no competing interests.

\section{Author details}

${ }^{1}$ Vector Borne Disease Unit, Papua New Guinea Institute of Medical Research, PO Box 378, Madang 511, MP, Papua New Guinea. ${ }^{2}$ Division of Population Health and Immunity, Walter and Eliza Hall Institute of Medical Research, 1 G Royal Parade, Parkville, VIC 3052, Australia. ${ }^{3}$ Present Address: Department of Biomedical Sciences, Institute of Tropical Medicine, Malariology Unit, Nationalestraat 155, 2000 Antwerp, Belgium. ${ }^{4}$ Medical Parasitology and Infection Biology, Swiss Tropical \& Public Health Institute, Socinstrasse 57, 4051 Basel, Switzerland. ${ }^{5}$ Center for Global Health and Diseases, Case Western
Reserve University, 10900 Euclid Ave, Cleveland, OH 44106, USA. ${ }^{6}$ Department of Medical Biology, University of Melbourne, Parkville, VIC 3010, Australia. ${ }^{7}$ Present Address: School of Medicine, Deakin University, Geelong and Burnet Institute, Melbourne, VIC, Australia. ${ }^{8}$ Department of Parasites and Insect Vectors, Malaria Parasites and Hosts Unit, Pasteur Institute, 25-28 rue du Docteur-Roux, 75724 Paris Cedex 15, France. ${ }^{9}$ Disease Elimination Program, Vector-borne Diseases and Tropical Public Health Group, Burnet Institute, 85 Commercial Rd, Melbourne, VIC 3004, Australia.

Received: 20 January 2020 Accepted: 20 May 2020

Published online: 05 June 2020

\section{References}

1. WHO. World Malaria Report 2019. Geneva: World Health Organization; 2019.

2. Mueller I, Bockarie M, Alpers M, Smith T. The epidemiology of malaria in Papua New Guinea. Trends Parasitol. 2003;19:253-9.

3. Genton B, al-Yaman F, Beck HP, Hii J, Mellor S, Narara A, et al. The epidemiology of malaria in the Wosera area, East Sepik Province, Papua New Guinea, in preparation for vaccine trials I Malariometric indices and immunity. Ann Trop Med Parasitol. 1995;89:359-76.

4. Cattani JA, Moir JS, Gibson FD, Ginny M, Paino J, Davidson W, et al. Smallarea variations in the epidemiology of malaria in Madang Province. P N G Med J. 1986;29:11-7.

5. Kasehagen LJ, Mueller I, McNamara DT, Bockarie MJ, Kiniboro B, Rare L, et al. Changing patterns of Plasmodium blood-stage infections in the Wosera region of Papua New Guinea monitored by light microscopy and high throughput PCR diagnosis. Am J Trop Med Hyg. 2006;75:588-96.

6. Mueller I, Rogerson S, Mola GD, Reeder JC. A review of the current state of malaria among pregnant women in Papua New Guinea. P N G Med J. 2008;51:12-6.

7. Rijken MJ, McGready R, Boel ME, Poespoprodjo R, Singh N, Syafruddin D, et al. Malaria in pregnancy in the Asia-Pacific region. Lancet Infect Dis. 2012;12:75-88

8. Burkot TR, Graves PM, Paru R, Wirtz RA, Heywood PF. Human malaria transmission studies in the Anopheles punctulatus complex in Papua New Guinea: sporozoite rates, inoculation rates, and sporozoite densities. Am J Trop Med Hyg. 1988;39:135-44.

9. Mueller I, Widmer S, Michel D, Maraga S, McNamara D, Kiniboro B, et al. High sensitivity detection of Plasmodium species reveals positive correlations between infections of different species, shifts in age distribution and reduced local variation in Papua New Guinea. Malar J. 2009;8:41.

10. Cooper RD, Waterson DG, Frances SP, Beebe NW, Pluess B, Sweeney AW. Malaria vectors of Papua New Guinea. Int J Parasitol. 2009:39:1495-501.

11. Foley DH, Paru R, Dagoro H, Bryan JH. Allozyme analysis reveals six species within the Anopheles punctulatus complex of mosquitoes in Papua New Guinea. Med Vet Entomol. 1993;7:37-48.

12. Bower JE, Dowton M, Cooper RD, Beebe NW. Intraspecific concerted evolution of the rDNA ITS1 in Anopheles farauti sensu stricto (Diptera: Culicidae) reveals recent patterns of population structure. J Mol Evol. 2008:67:397-411.

13. Cooper RD, Waterson DG, Frances SP, Beebe NW, Sweeney AW. Speciation and distribution of the members of the Anopheles punctulatus (Diptera: Culicidae) group in Papua New Guinea. J Med Entomol. 2002;39:16-27.

14. Benet A, Mai A, Bockarie F, Lagog M, Zimmerman P, Alpers MP, et al. Polymerase chain reaction diagnosis and the changing pattern of vector ecology and malaria transmission dynamics in Papua New Guinea. Am J Trop Med Hyg. 2004;71:277-84.

15. Mehlotra RK, Lorry K, Kastens W, Miller SM, Alpers MP, Bockarie M, et al. Random distribution of mixed species malaria infections in Papua New Guinea. Am J Trop Med Hyg. 2000;62:225-31.

16. Kazura JW, Siba PM, Betuela I, Mueller I. Research challenges and gaps in malaria knowledge in Papua New Guinea. Acta Trop. 2012;121:274-80.

17. Desowitz RS, Spark RA. Malaria in the Maprik area of the Sepik region, Papua New Guinea: 1957-1984. Trans R Soc Trop Med Hyg. 1987:81:175-6.

18. Hetzel M, Pulford J, Gouda H, Hodge A, Siba P, Mueller I. The Papua New Guinea National Malaria Control Program: primary outcome \& impact 
indicators, 2009-2014. Goroka: Papua New Guinea Institute of Medical Research; 2014.

19. Pulford J, Kurumop SF, Ura Y, Siba PM, Mueller I, Hetzel MW. Malaria case management in Papua New Guinea following the introduction of a revised treatment protocol. Malar J. 2013;12:433.

20. Hetzel MW, Gideon G, Lote N, Makita L, Siba PM, Mueller I. Ownership and usage of mosquito nets after four years of large-scale free distribution in Papua New Guinea. Malar J. 2012;11:192.

21. Hetzel MW, Choudhury AA, Pulford J, Ura Y, Whittaker M, Siba PM, et al. Progress in mosquito net coverage in Papua New Guinea. Malar J. 2014;13:242.

22. Hetzel MW, Morris H, Tarongka N, Barnadas C, Pulford J, Makita L, et al. Prevalence of malaria across Papua New Guinea after initial roll-out of insecticide-treated mosquito nets. Trop Med Int Health. 2015;20:1745-55.

23. Hetzel MW, Pulford J, Maraga S, Barnadas C, Reimer L, Tavul L, et al. Evaluation of the Global Fund-supported National Malaria Control Program in Papua New Guinea, 2009-2014. P N G Med J. 2014;57:7-29.

24. Hetzel MW, Reimer $\sqcup$, Gideon G, Koimbu G, Barnadas C, Makita L, et al. Changes in malaria burden and transmission in sentinel sites after the roll-out of long-lasting insecticidal nets in Papua New Guinea. Parasit Vectors. 2016;9:340.

25. Koepfli C, Ome-Kaius M, Jally S, Malau E, Maripal S, Ginny J, et al. Sustained malaria control over an 8-year period in Papua New Guinea: The challenge of low-density asymptomatic Plasmodium infections. J Infect Dis. 2017;216:1434-43.

26. Rovira-Vallbona E, Contreras-Mancilla JJ, Ramirez R, Guzman-Guzman M, Carrasco-Escobar G, Llanos-Cuentas A, et al. Predominance of asymptomatic and sub-microscopic infections characterizes the Plasmodium gametocyte reservoir in the Peruvian Amazon. PLoS Negl Trop Dis. 2017;11:e0005674.

27. Tadesse FG, Slater HC, Chali W, Teelen K, Lanke K, Belachew M, et al. The relative contribution of symptomatic and asymptomatic Plasmodium vivax and Plasmodium falciparum infections to the infectious reservoir in a low-endemic setting in Ethiopia. Clin Infect Dis. 2018;66:1883-91.

28. Bousema T, Griffin JT, Sauerwein RW, Smith DL, Churcher TS, Takken W, et al. Hitting hotspots: spatial targeting of malaria for control and elimination. PLoS Med. 2012;9:e1001165.

29. Laman M, Moore BR, Benjamin J, Padapu N, Tarongka N, Siba P, et al. Comparison of an assumed versus measured leucocyte count in parasite density calculations in Papua New Guinean children with uncomplicated malaria. Malar J. 2014;13:145.

30. McNamara DT, Kasehagen LJ, Grimberg BT, Cole-Tobian J, Collins WE, Zimmerman PA. Diagnosing infection levels of four human malaria parasite species by a polymerase chain reaction/ligase detection reaction fluorescent microsphere-based assay. Am J Trop Med Hyg. 2006;74:413-21.

31. Wampfler R, Mwingira F, Javati S, Robinson L, Betuela I, Siba P, et al. Strategies for detection of Plasmodium species gametocytes. PLoS ONE. 2013;8:e76316.

32. Rosanas-Urgell A, Mueller D, Betuela I, Barnadas C, Iga J, Zimmerman PA, et al. Comparison of diagnostic methods for the detection and quantification of the four sympatric Plasmodium species in field samples from Papua New Guinea. Malar J. 2010;9:361.

33. Schoepflin S, Valsangiacomo F, Lin E, Kiniboro B, Mueller I, Felger I. Comparison of Plasmodium falciparum allelic frequency distribution in different endemic settings by high-resolution genotyping. Malar J. 2009:8:250.

34. Koepfli C, Mueller I, Marfurt J, Goroti M, Sie A, Oa O, et al. Evaluation of Plasmodium vivax genotyping markers for molecular monitoring in clinical trials. J Infect Dis. 2009:199:1074-80.

35. WHO. Haemoglobin concentrations for the diagnosis of anaemia and assessment of severity. Vitamin and Mineral Nutrition Information System. Geneva: World Health Organization; 2011.

36. Koepfli C, Robinson LJ, Rarau P, Salib M, Sambale N, Wampfler R, et al. Blood-stage parasitaemia and age determine Plasmodium falciparum and P. vivax gametocytaemia in Papua New Guinea. PLoS ONE. 2015;10:e0126747.

37. Hii JL, Smith T, Mai A, Mellor S, Lewis D, Alexander N, et al. Spatial and temporal variation in abundance of Anopheles (Diptera:Culicidae) in a malaria endemic area in Papua New Guinea. J Med Entomol. 1997;34:193-205.
38. Namosha E, Mueller I, Kastens W, Kiele R, Kasehagen L, Siba PM. Mapping the prevalence of malaria in rural Papua New Guinea using a geographic information system. P N G Med J. 2010;53:5-14.

39. Myers WP, Myers AP, Cox-Singh J, Lau HC, Mokuai B, Malley R. Microgeographic risk factors for malarial infection. Malar J. 2009:8:27.

40. Lengeler C. Insecticide-treated bed nets and curtains for preventing malaria. Cochrane Database Syst Rev. 2004:CD000363.

41. Gamble C, Ekwaru JP, ter Kuile FO. Insecticide-treated nets for preventing malaria in pregnancy. Cochrane Database Syst Rev. 2006:CD003755.

42. Graves PM, Brabin BJ, Charlwood JD, Burkot TR, Cattani JA, Ginny M, et al. Reduction in incidence and prevalence of Plasmodium falciparum in under-5-year-old children by permethrin impregnation of mosquito nets. Bull World Health Organ. 1987;65:869-77.

43. Howard SC, Omumbo J, Nevill C, Some ES, Donnelly CA, Snow RW. Evidence for a mass community effect of insecticide-treated bednets on the incidence of malaria on the Kenyan coast. Trans R Soc Trop Med Hyg. 2000;94:357-60.

44. Binka FN, Indome F, Smith T. Impact of spatial distribution of permethrinimpregnated bed nets on child mortality in rural northern Ghana. Am J Trop Med Hyg. 1998;59:80-5.

45. Hii JL, Smith T, Vounatsou P, Alexander N, Mai A, Ibam E, et al. Area effects of bednet use in a malaria-endemic area in Papua New Guinea. Trans $R$ Soc Trop Med Hyg. 2001;95:7-13.

46. Hawley WA, Phillips-Howard PA, ter Kuile FO, Terlouw DJ, Vulule JM, Ombok M, et al. Community-wide effects of permethrin-treated bed nets on child mortality and malaria morbidity in western Kenya. Am J Trop Med Hyg. 2003;68:121-7.

47. Rodriguez-Rodriguez D, Maraga S, Lorry L, Robinson LJ, Siba PM, Mueller I, et al. Repeated mosquito net distributions, improved treatment, and trends in malaria cases in sentinel health facilities in Papua New Guinea. Malar J. 2019;18:364.

48. Reimer LJ, Thomsen EK, Koimbu G, Keven JB, Mueller I, Siba PM, et al. Malaria transmission dynamics surrounding the first nationwide long-lasting insecticidal net distribution in Papua New Guinea. Malar J. 2016;15:25.

49. Clark TD, Greenhouse B, Njama-Meya D, Nzarubara B, Maiteki-Sebuguzi C, Staedke SG, et al. Factors determining the heterogeneity of malaria incidence in children in Kampala, Uganda. J Infect Dis. 2008;198:393-400.

50. Oesterholt MJ, Bousema JT, Mwerinde OK, Harris C, Lushino P, Masokoto A, et al. Spatial and temporal variation in malaria transmission in a low endemicity area in northern Tanzania. Malar J. 2006;5:98.

51. Staedke SG, Nottingham EW, Cox J, Kamya MR, Rosenthal PJ, Dorsey G. Proximity to mosquito breeding sites as a risk factor for clinical malaria episodes in an urban cohort of Ugandan children. Am J Trop Med Hyg. 2003;69:244-6.

52. Zimmerman PA, Patel SS, Maier AG, Bockarie MJ, Kazura JW. Erythrocyte polymorphisms and malaria parasite invasion in Papua New Guinea. Trends Parasitol. 2003;19:250-2.

53. Kasehagen LJ, Mueller I, Kiniboro B, Bockarie MJ, Reeder JC, Kazura JW, et al. Reduced Plasmodium vivax erythrocyte infection in PNG Duffynegative heterozygotes. PLoS ONE. 2007;2:e336.

54. Patel SS, Mehlotra RK, Kastens W, Mgone CS, Kazura JW, Zimmerman PA. The association of the glycophorin C exon 3 deletion with ovalocytosis and malaria susceptibility in the Wosera, Papua New Guinea. Blood. 2001;98:3489-91.

55. Rosanas-Urgell A, Lin E, Manning L, Rarau P, Laman M, Senn N, et al. Reduced risk of Plasmodium vivax malaria in Papua New Guinean children with Southeast Asian ovalocytosis in two cohorts and a case-control study. PLoS Med. 2012;9:e1001305.

56. Bannister-Tyrrell M, Xa NX, Kattenberg JH, Van Van N, Dung VKA, Hieu TM, et al. Micro-epidemiology of malaria in an elimination setting in Central Vietnam. Malar J. 2018;17:119.

57. Schultz L, Wapling J, Mueller I, Ntsuke PO, Senn N, Nale J, et al. Multilocus haplotypes reveal variable levels of diversity and population structure of Plasmodium falciparum in Papua New Guinea, a region of intense perennial transmission. Malar J. 2010;9:336.

58. Jennison C, Arnott A, Tessier N, Tavul L, Koepfli C, Felger I, et al. Plasmodium vivax populations are more genetically diverse and less structured than sympatric Plasmodium falciparum populations. PLoS Negl Trop Dis. 2015;9:e0003634. 
59. Ome-Kaius M, Kattenberg JH, Zaloumis S, Siba M, Kiniboro B, Jally S, et al. Differential impact of malaria control interventions on $P$. falciparum and P. vivax infections in young Papua New Guinean children. BMC Med. 2019;17:220.

60. Lin E, Kiniboro B, Gray L, Dobbie S, Robinson L, Laumaea A, et al. Differential patterns of infection and disease with $P$. falciparum and $P$. vivax in young Papua New Guinean children. PLoS ONE. 2010;5:e9047.

61. Mueller I, Schoepflin S, Smith TA, Benton KL, Bretscher MT, Lin E, et al. Force of infection is key to understanding the epidemiology of Plasmodium falciparum malaria in Papua New Guinean children. Proc Natl Acad Sci USA. 2012;109:10030-5.

62. Hetzel MW, Pulford J, Ura Y, Jamea-Maiasa S, Tandrapah A, Tarongka N, et al. Insecticide-treated nets and malaria prevalence, Papua New Guinea, 2008-2014. Bull World Health Organ. 2017;95:695-705

63. Woolhouse ME, Dye C, Etard JF, Smith T, Charlwood JD, Garnett GP, et al. Heterogeneities in the transmission of infectious agents: implications for the design of control programs. Proc Natl Acad Sci USA. 1997;94:338-42.

64. Moonen B, Cohen JM, Snow RW, Slutsker L, Drakeley C, Smith DL, et al. Operational strategies to achieve and maintain malaria elimination. Lancet. 2010:376:1592-603.
65. Bousema T, Drakeley C, Gesase S, Hashim R, Magesa S, Mosha F, et al. Identification of hot spots of malaria transmission for targeted malaria control. J Infect Dis. 2010;201:1764-74.

66. Bautista CT, Chan AS, Ryan JR, Calampa C, Roper MH, Hightower AW, et al. Epidemiology and spatial analysis of malaria in the Northern Peruvian Amazon. Am J Trop Med Hyg. 2006;75:1216-22.

67. Bejon P, Williams TN, Liljander A, Noor AM, Wambua J, Ogada E, et al. Stable and unstable malaria hotspots in longitudinal cohort studies in Kenya. PLoS Med. 2010;7:e1000304

68. Robinson LJ, Wampfler R, Betuela I, Karl S, White MT, Li Wai Suen CS, et al. Strategies for understanding and reducing the Plasmodium vivax and Plasmodium ovale hypnozoite reservoir in Papua New Guinean children: a randomised placebo-controlled trial and mathematical model. PLoS Med. 2015;12:e1001891.

\section{Publisher's Note}

Springer Nature remains neutral with regard to jurisdictional claims in published maps and institutional affiliations.
Ready to submit your research? Choose BMC and benefit from:

- fast, convenient online submission

- thorough peer review by experienced researchers in your field

- rapid publication on acceptance

- support for research data, including large and complex data types

- gold Open Access which fosters wider collaboration and increased citations

- maximum visibility for your research: over $100 \mathrm{M}$ website views per year

At BMC, research is always in progress.

Learn more biomedcentral.com/submissions 